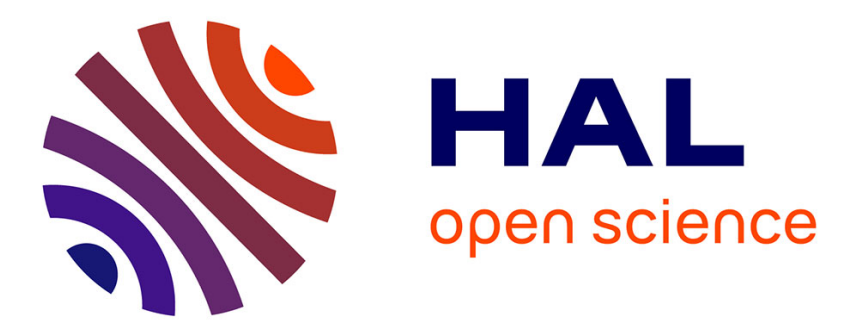

\title{
Getting from Sea to Nurseries: Considering Tidal Dynamics of Juvenile Habitat Distribution and Connectivity in a Highly Modified Estuarine Riverscape Céline Le Pichon, Maria Alp
}

\section{- To cite this version:}

Céline Le Pichon, Maria Alp. Getting from Sea to Nurseries: Considering Tidal Dynamics of Juvenile Habitat Distribution and Connectivity in a Highly Modified Estuarine Riverscape. Ecosystems, In press, 10.1007/s10021-020-00536-1 . hal-03130902

\section{HAL Id: hal-03130902 https://hal.science/hal-03130902}

Submitted on 3 Feb 2021

HAL is a multi-disciplinary open access archive for the deposit and dissemination of scientific research documents, whether they are published or not. The documents may come from teaching and research institutions in France or abroad, or from public or private research centers.
L'archive ouverte pluridisciplinaire HAL, est destinée au dépôt et à la diffusion de documents scientifiques de niveau recherche, publiés ou non, émanant des établissements d'enseignement et de recherche français ou étrangers, des laboratoires publics ou privés. 


\section{$1 \quad$ Full title:}

2 Getting from sea to nurseries: considering tidal dynamics of juvenile habitat

3 distribution and connectivity in a highly-modified estuarine riverscape

4

$5 \quad$ Short title: Getting from sea to nurseries

6

7

8 Authors : Maria Alp ${ }^{1,2}$, Céline Le Pichon ${ }^{1}$

9

10 Author affiliations:

$11{ }^{1}$ Université Paris-Saclay, INRAE, UR HYCAR, 1 rue Pierre-Gilles de Gennes, 92761,

12 Antony, France

$13 \quad{ }^{2}$ INRAE, UR Riverly, 5 rue de la Doua, 69625, Villeurbanne, France

14

15 Corresponding author: Maria Alp, maria.alp@inrae.fr, +33 472208796.

16

17 Author contributions: MA and CLP contributed equally to study design and manuscript 18 preparation. MA led the data preparation and least-cost modelling. 


\section{Abstract}

20 Productive and ecologically highly valuable ecosystems, macrotidal estuaries are also

21 characterised by complex habitat and connectivity dynamics driven by tidal and freshwater

22 influence. Organisms living in these constantly changing systems have to match their movement patterns to the shifting habitat mosaic using available windows of connectivity to access habitat patches of interest. This appears particularly important for the juvenile stages of many fish species colonising shallow and intertidal areas of the estuaries as summer nurseries.

We apply tools from landscape ecology to investigate the estuarine habitat and connectivity dynamics on the example of juvenile seabass (Dicentrarchus labrax). We test, under which conditions spatio-temporal bottlenecks to estuarine nursery colonisation may emerge for this species in a human-modified estuary. Combining a hydrodynamic model of the Seine estuary with remote-sensing data allows us to capture structural changes in habitat availability and connectivity at the estuarine scale and at a fine spatio-temporal resolution. With chronological least-cost modelling of successive tidal steps, we assess patterns of nursery accessibility and estimate tidal colonisation fronts for different mobility scenarios. We show that, at certain hydrological conditions, tidal water level variation causes local disruptions of habitat availability and connectivity, creating temporary bottlenecks for seabass juveniles' movement. Fish mobility appears determinant for their vulnerability to these connectivity disruptions. Our approach allows for quantitative assessment and visualisation of riverscape complexity related to tidal dynamics. It is applicable to other highly dynamic ecosystems, where the mobile nature of connectivity and habitats needs to be integrated into conservation and management planning. 
42 Keywords: least-cost modelling, spatio-temporal hydrodynamics, functional connectivity,

43 habitat patch dynamics, tidal cycle, dispersal, nursery habitats, Seine estuary, European

44 seabass Dicentrarchus labrax

45 Manuscript highlights

46 - Tidal estuarine habitat distribution and connectivity change on an hourly scale

47 - Transient bottlenecks to movement emerge in estuaries with modified topography

48 - Juvenile fish sensitivity to these bottlenecks depends on their swimming capacity 


\section{Introduction}

When speaking of animal habitats in a landscape perspective, we may be inclined to imagine clearly defined stable patches either isolated or connected by animal movement. In reality, environmental parameters delimiting habitats and determining landscape connectivity are often subject to substantial fluctuations. In dynamic ecosystems, the distribution of habitat patches changes spatially over time ("shifting habitat mosaic", Stanford and others 2005; Wimberly 2006) and so does their accessibility characterised by "transient windows of connectivity" (Zeigler and Fagan 2014). Several spatio-temporal scales may be involved in such dynamics determined by natural or anthropogenic drivers. For instance, distribution of vegetation cover (and thus of habitat patches) in a landscape may be re-set by volcano eruptions or earthquakes occurring on the temporal scales of centuries or thousands of years, or by more frequently recurring disturbances, such as fire or violent storms (Zeigler and Fagan 2014). In river floodplains, large-scale "reshuffling” of habitat mosaic results primarily from major flood events (Hohensinner and others 2011), while natural or artificial fluctuations of environmental parameters (e.g. temperature or water level), occurring on the daily or hourly basis, may affect habitat patch distribution and connectivity at finer spatiotemporal scales (Capra and others 2017; Tonolla and others 2010).

Theoretical modelling has allowed to explore the drivers of metapopulation persistence in dynamic mosaic landscapes (Fahrig 1992; Keymer and others 2000), demonstrating the importance of matching between spatio-temporal scales of landscape dynamics and the life history traits of an organism, such as its life span and dispersal capacity. Animal life cycle may involve movement related to changes of vital space between life stages, most evident in species with complex life cycles shifting between terrestrial and aquatic, or marine and freshwater environments. Furthermore, within the vital space of each life stage, daily or seasonal movements between different habitat types may also occur 
(Figure 1). The term "connectivity fractal" has been suggested by Sheaves (2009) to describe the pattern produced by «the hierarchy of migrations at a variety of scales that connect a variety of habitats in complex ways".

For understanding population dynamics within a landscape, it is crucial to link the habitat-patch-dynamics perspective with a temporal perspective on the organism's life history including its changing dispersal capacity (Wiens 1976). This involves considering landscape structure and landscape connectivity in terms of propensity or resistance to movement (Baguette and others 2013; Taylor and others 1993). The landscape may thus be seen as an organism- and stage-specific map of habitat patches connected by "highways", "backroads", "barriers" etc. Furthermore, as the sequence of life cycle events occurs in a certain nonrandom and non-reversible order, taking a chronological approach is necessary for understanding "life cycle connectivity" within a given landscape.

Empirical studies of habitat distribution and landscape connectivity are challenging in large dynamic ecosystems, as they require spatio-temporally explicit data acquired at appropriate scales and a sufficiently fine resolution. Where direct observations of movement are difficult, functional connectivity modelling offers a way of quantifying and predicting habitat distribution and accessibility (Adriaensen and others 2003). It became particularly promising in the view of technological developments in remote-sensing and environmental modelling allowing for access to continuous environmental data with high resolution in space and time (Carbonneau and Piégay 2012; Neumann and others 2015). When supported by good knowledge of species ecology and dispersal capacity, these tools allow producing map sequences of habitat patch distribution and landscape permeability for movement. Habitat accessibility can then be assessed with least-cost modelling, whereby leastcost paths correspond to "effective distances" between habitat patches estimated to have the lowest energetic cost and a maximum potential of survival (Adriaensen and others 2003; 
Zeller and others 2012). This approach has allowed identifying terrestrial wildlife corridors in conservation context at the scales from hundreds of kilometers for large mammals (Rouget and others 2006) to few hundreds of meters for amphibians (Ray and others 2002) and invertebrates (Sutcliffe and others 2003). It has also been applied in riverscapes (Foubert and others 2019; Hanke and others 2014) and seascapes (Caldwell and Gergel 2013), but, until recently, hardly used in highly dynamic aquatic systems (but see Foubert and others 2019). Macrotidal estuaries represent an ecosystem with particularly complex habitat dynamics involving several temporal scales. Daily tidal dynamics interact here with seasonal patterns of freshwater discharge, driving environmental variability (salinity, water level, current velocity and direction) and creating high spatio-temporal habitat heterogeneity. The extremes of such variation can be observed in the intertidal habitats (tidal creeks, salt marshes, mudflats), transformed within hours from nearly terrestrial at low tide to aquatic at high tide. These highly productive habitats are of particular ecological value, as they are an important part of nurseries for many fish and invertebrate species (Bretsch and Allen 2006; Rountree and Able 2007), representing functional habitats, which contribute to their feeding, growth and survival at early stages and offer refuge from predators (Cattrijsse and Hampel 2006; Rountree and Able 2007). Importantly, spatial distribution of optimal nursery habitat patches changes with the progression of the tide due to water level and flow velocity fluctuations creating a true "shifting habitat mosaic" on very short temporal scales. Juveniles of many marine and estuarine fish species have adapted their behaviour to the tidal cycle, effectuating daily migrations to temporarily available habitats (Gibson 2003; Laffaille and others 2001; Martinho and others 2008) or using strong tidal currents (selective tidal transport) to advance on a larger spatial scale in a required direction (Forward and Tankersley 2001). 
Many of today's estuaries have been strongly degraded by human activities (Lotze and

124 others 2006). Strategical nodes for navigation and integrators of basin-scale processes, they have a long history of morphological and physico-chemical alteration: channelization, shoreline armoring, as well as upstream-derived impacts such as pollution, changes of river

127 flow regime, or sediment transport. This could have several effects on the habitat dynamics in

128 the estuarine intertidal zones. First, habitat patch availability may be reduced through

129 modification of estuarine morphology either throughout the tidal cycle or at its specific steps.

130 Second, connectivity between available habitat patches might be temporarily disrupted during

131 the tidal cycle, impeding the organisms, which colonise them, to complete their tidal

132 migration cycle.

133 The objective of our work was to quantify fish habitat availability and accessibility in

134 a macrotidal human-impacted estuary using a chronological map-based modelling approach.

135 We applied tools from functional landscape modelling developed for riverscapes (Roy and Le

136 Pichon 2017) to the case of tidal migration of juvenile European seabass (Dicentrarchus

137 labrax) towards summer nurseries of the Seine estuary at the moment of their colonisation.

138 Our study organism is a marine species with a well-documented life-cycle and extensive

139 experimental evidence on swimming capacity at different stages. Specific questions we asked

140 for seabass were: i) How do water level fluctuations affect the extent and distribution of its

141 estuarine nursery habitats? ii) Does a morphologically modified estuary allow for a

142 continuous functional connectivity of the nursery habitats on a large scale and thus for their

143 colonisation by early juveniles?

144 To address these questions, we considered two temporal scales of variation and 145 conducted both an intra-annual and an intra-tidal analysis. We first tested for the effects of a 146 range of tidal coefficients (TC) and two discharge levels on seabass nursery availability at 147 high tide. Then, for two contrasted cases of hydrological conditions, we quantified nursery 
and ebb habitat availability at different steps of the tidal cycle and modelled initial

149 colonisation of these habitats by seabass juveniles. Throughout the paper we used the term

150 "estuarine colonisation" to designate the process of first access of young juveniles from the

151 estuarine mouth to the whole extent of estuarine nurseries up to the upstream limit of their

152 salinity preferences. This large-scale and potentially multi-step advancement profits from

153 selective tidal transport during the flood stages of the tidal cycles. "Estuarine colonisation"

154 results in the establishment of juveniles in certain areas of the estuary, where they were not

155 initially present, and where they can then enter daily cycles of moving between patches of

156 habitat available at different moments of the tide, or "tidal migrations" (Rountree and Able

157 2007, Sheaves 2009).

158

159 Materials and Methods

160 Study site

161 The Seine estuary (Figure 2) is an example of a large macrotidal estuary of the European

162 Atlantic coast highly modified by human activities (Tecchio and others 2016). It is

163 characterised by a semidiurnal regime and tidal amplitude of $8.5 \mathrm{~m}$ in the mouth area (Lafite

164 and Romaña 2001). The spatial extent of tidal waters covers $170 \mathrm{~km}$ of river length, and is

165 limited by the Poses dam upstream. The mean annual Seine river discharge measured at Poses

166 is $450 \mathrm{~m}^{3} \mathrm{~s}^{-1}\left(50\right.$ to $\left.2200 \mathrm{~m}^{3} \mathrm{~s}^{-1}\right)$.

167 Originally, the mouth of the Seine estuary was a large and shallow braided system

168 characterised by islands, mobile sandbanks, and extensive intertidal areas with mudflats and

169 salt marshes (Avoine and others 1981; Lesourd and others 2016; Figure 2), while the

170 upstream freshwater part was a meandering river with numerous islands, shoals and pools.

171 Since 1834, the Seine estuary has been experiencing morphological and sedimentary 
172 modifications to secure boat traffic and stabilise river flow through channel containment,

173 dredging, diking and island removal. Furthermore, the Normandy Bridge construction (1995),

174 and the new port extension of Le Havre (2006) have considerably modified the structural

175 aspects and the hydrodynamic conditions at the Seine estuary, causing further loss of

176 intertidal habitats. Separating the main channel from the riverbanks by submersible dikes has

177 narrowed the estuary (Grasso and Le Hir 2019) and restricted its lateral connectivity.

178 Altogether, the estuary has lost $78 \%$ of its intertidal areas and $80 \%$ of the islands since the

179 beginning of the 20th century (Lafite and Romaña 2001; Cuvilliez and others 2009), with

$18076 \%$ of banks in the estuarine mouth being diked (Foussard and others 2010). The nursery

181 capacity of the Seine estuary has been strongly affected by these changes, for instance, for

182 flatfish, it has been estimated to be reduced by $42 \%$ (Rochette and others 2010).

\section{Study species}

184 European seabass (Dicentrarchus labrax) is a highly exploited fish species of the North East

185 Atlantic (NEA) coast, whose northern stock has been declining over recent years (López and

186 others 2015). The life cycle of NEA populations takes place between marine, coastal and

187 brackish habitats. Seabass spawn offshore in early spring with post-larvae spending about a

188 month in the unstratified waters of the English Channel (Jennings and Pawson 1992). Nursery

189 settlement at the NEA coast occurs between April and September, about 2-3 months upon

190 hatching, followed by the metamorphosis into juveniles between 50 and 110 days post-hatch

191 (Jennings and Pawson 1992; López and others 2015). In spring, once the water temperatures

192 increase, assisted by tidal currents, seabass juveniles colonise coastal and estuarine nurseries

193 and start daily migrations between subtidal and intertidal habitats in poly- and mesohalin

194 zones (Jennings and Pawson 1992; Cabral and Costa 2001). A high local site fidelity has been

195 observed, with juveniles staying for longer periods in proximity of the same nursery areas 
196 (Green and others 2012). The tidal migrations continue until the onset of cold temperatures in

197 the fall, when the juveniles move to deeper areas of the estuary or to coastal habitats (Kelley

198 1986). Young seabass spend the first 2-4 years of their life in close association with the

199 estuaries, after which they shift to living in marine and coastal environments (López and 200 others 2015).

201 First-year juveniles of seabass start tidal migrations at the size of 10-15 mm (Jennings 202 and others 1991) and reach about $60 \mathrm{~mm}$ at the end of their first summer (Kelley 2002).

203 Dispersal capacity of early stages is rather low (with expected in situ swimming speeds of 204 about $0.03-0.13 \mathrm{~m} \mathrm{~s}^{-1}$ for fish under $30 \mathrm{~mm}$; Leis and others 2012). As many marine and 205 catadromous species, juveniles of seabass appear to have the capacity of using selective tidal 206 transport and are guided by environmental cues, such as temperature and low salinity (Pickett 207 and Pawson 1994; López and others 2015). The latter facilitate and orient their movement 208 towards the nurseries located in tidal estuaries and coastal salt marshes or mangroves 209 (Jennings and Pawson 1992). Transport with tidal currents may thus be assumed as the 210 predominant mechanism for estuarine colonisation, but it may be complemented by small211 scale movement in shallow areas along the shores or by using back eddies or other slack water 212 to avoid strong currents in the channel (Pickett and Pawson 1994). Furthermore, vertical 213 position selection in the water column presumably facilitating the adjustment of their 214 movement to flow velocity patterns has been reported for seabass larvae and juveniles (López 215 and others 2015). Own swimming capacity of juveniles increases rapidly with growth and 216 reaches about $0.3-0.6 \mathrm{~m} \mathrm{~s}^{-1}$ by the end of the first year. Optimal speeds for late juveniles are 217 predicted at temperatures between 7 and $22^{\circ} \mathrm{C}$; Claireaux and others 2006). The highest abundances of seabass juveniles are found in the euhaline and mesohaline 219 zones (Selleslagh and Amara 2008). Shallow ( $<2 \mathrm{~m}$ deep), turbid and muddy habitats typical 220 of mudflats, salt marshes and tidal creeks have been described as rich feeding grounds 
particularly prone to becoming seabass nursery habitats (Cabral and Costa 2001; Cattrijsse and others 1994) and recent stable isotope data confirm an important contribition of intertidal zones to their diet (Day \& Brind'Amour, unpublished data for the Seine estuary). Field observations indicate that most of the seabass tidal feeding occurs during the flood and the high tide (Laffaille and others 2001). Nearly no quantitative information exists on their behaviour during the ebb and the low tide. During these tidal phases they have been observed to stay in the areas of low flow velocities in proximity to the high-tide nurseries (personal communications E.Feunteun, S.Duhamel), with some individuals remaining in warm tidal pools isolated from the main stream during low tide (Pickett and Pawson 1994; Kelley 1986). In the Seine estuary, this behaviour has also been reported in the intertidal areas behind the dikes (pers. communication E.Feunteun). However, as this behavioural strategy involves substantial risks (desiccation, exposure to predators), we may expect only a very minor fraction of the population to use it.

\section{GIS-based analysis}

\section{Water depth and habitat mapping}

Based on temperature and discharge time series at the estuarine mouth (Online Resource 1), we identified the period between April $1^{\text {st }}$ and November $15^{\text {th }}$ as the main period of nursery use. This corresponds to the time window following the first spring river floods and when temperature exceeds $+10^{\circ} \mathrm{C}$ (a physiological threshold of feeding activity; Pastoureaud 1991). For the intra-annual comparison of habitat distribution, we used ranking analysis and selected two discharge levels and four tidal coefficients (TC) covering the variability of hydrological conditions occurring during the time window considered: $250 \mathrm{~m}^{3} \mathrm{~s}^{-1}$ and $800 \mathrm{~m}^{3} \mathrm{~s}^{-1}$ exceeded $60 \%$ and $5 \%$ of time respectively, and TC 45, TC 65, TC 80 and TC 115 exceeded $85 \%, 60 \%$, $35 \%$ and $2 \%$ of time respectively. Tidal coefficients as high as 115 occurred during extreme 
spring and fall tides, while variation in tidal coefficients in the summer was well covered by the range between TC 45 and TC 85 (Supplementary Figure S1c).

High tide water levels across the estuary were estimated statistically using a model

249 based on the interpolation of tidal heights at eighteen gauges distributed over the estuary between Honfleur and Poses. For the intra-tidal analysis, a 3D-hydrodynamic model of the

251 Seine estuary was used to calculate water level, current velocity and salinity for a

252 hydrologically average year (2010; Supplementary Figure S1b) at a time step of 15 min 253 (MARS-3D; Le Hir and Lafite 2012). We expected habitat surface decrease to be the major 254 driver of fragmentation and connectivity disruption. We thus selected one discharge level $255\left(250 \mathrm{~m}^{3} \mathrm{~s}^{-1}\right)$ and two tidal coefficients (TC 52 and TC 85) observed in combination in 2010 to 256 cover hydrological conditions resulting in most contrasting patterns of high tide habitat 257 distribution, and achieve the closest possible match to the intra-annual analysis. A regular square grid with each cell covering $5 \mathrm{~m}$ x $5 \mathrm{~m}$, was chosen for all GIS-based analyses as a compromise between i) the precision of habitat patch and barrier (e.g. submersible dikes) representation and ii) the calculation time necessary for least-cost modelling. For both intra-annual and intra-tidal analyses, maps of water depths were produced

262 for each discharge level-TC combination and for each considered tidal step based on the 263 difference between the estimated water level and LIDAR-based topo-bathymetric data (GIP Seine Aval) for each cell of the grid.

In the following, when referring to the intra-tidal analysis, we use the term "tidal time 266 point" $\left(t_{N}\right)$ to delimit a specific point ("snapshot") of environmental conditions in time, while 267 "tidal time step" corresponds to the conditions in the interval $\left(t_{\mathrm{N}}-\mathrm{t}_{\mathrm{N}+1}\right)$ between two 268 subsequent tidal time points. Flood thus starts at $\mathrm{t}_{1}(0 \mathrm{~min})$ and ends with $\mathrm{t}_{14}(195 \mathrm{~min})$, high 269 tide occurs between $\mathrm{t}_{14}$ and $\mathrm{t}_{24}(345 \mathrm{~min})$ and the ebb between $\mathrm{t}_{24}$ and $\mathrm{t}_{49}(720 \mathrm{~min})$ 270 (Supplementary Figure S2). To capture key tidal changes of habitat availability and 
connectivity, the flood and the ebb were divided into five time steps each (e.g. $t_{1}-t_{5}, t_{5}-t_{7}$ etc.)

272 based on two criteria: the degree of estuarine dike submergence (Figure 2) and the degree of

273 tidal creek inundation along the upstream-downstream gradient (see insets in Figure 3).

The spatial extent considered for this study was determined by the area with the mean salinity above $0.5 \%$ over the tidal cycle at median TC (70). In the NEA estuaries, the postlarvae have been reported to arrive to coastal areas early in spring and spend at least 30 days in the proximity of the estuaries before colonising them (Jennings and Pawson, 1992). Basing upon expert opinion, we assumed that in spring, early juveniles occupy moderately shallow areas of the mouth of the Seine before entering the tidal cycle to access intertidal nurseries for the first time (personal communication S.Duhamel). The departure habitat for colonisation 281 modelling was thus defined as estuarine mouth areas with 0.2-5 m depth (at low tide) and a 282 minimal patch size of 10 ha (Supplementary Figure S3). Tidal seabass nurseries were defined 283 as shallow areas (0.2-2 $\mathrm{m}$ at each time step of the flood) with either sandy or muddy substrate (Fritsch 2005). Their distribution was estimated by intersecting maps of dominant (>50\%) bottom substrates in subtidal and intertidal areas (Online Resource 2) with water depth maps. 286 Having limited information on the low tide habitat selection, we chose a simple definition as 287 shallow areas (0.2-2 $\mathrm{m})$ with current velocities not exceeding maximum juvenile swimming 288 capacity tested $\left(<0.3 \mathrm{~m} \mathrm{~s}^{-1}\right)$ corresponding functionally to "refuge habitats". The spatial resolution of our data did not allow us to consider temporary tidal pools as potential refuge 290 habitats.

$$
\text { A value of } 100 \mathrm{~m}^{2} \text { was chosen as a minimal patch size, smaller elements being }
$$

292 visually identified as geomatic artefacts. For the intra-annual analysis, only high-tide nursery 293 habitats were mapped, while for the intra-tidal analysis, both nursery and refuge habitats were 294 mapped at five time points of the flood $\left(t_{5}, t_{7}, t_{9}, t_{11}, t_{14}\right)$ and ebb $\left(t_{27}, t_{30}, t_{34}, t_{39}, t_{45}\right)$. To 295 compare habitat distribution along the longitudinal (upstream-downstream) and horizontal 
(north-south) axes of the estuary, we distinguished between six sectors: the estuarine mouth,

297 the area with tidal creeks, and the upstream channel located either to the north or to the south

298 of the main channel (see Online Resource 3 for a map).

299

300

301

302

303

304

305

306

307

308

309

\section{Resistance mapping}

We assumed that key factors driving estuarine permeability for the movement of early seabass juveniles were current velocities in the areas submerged at each tidal time step. Resistance values were assigned to each map pixel based on the current velocities. The current could thus i) be neutral to movement $(\mathrm{R}=1)$; ii) facilitate movement $(\mathrm{R}<1)$; iii) impede movement $(\mathrm{R}>1)$; or iv) be so high as to be avoided by the juveniles and thus considered in the model as an impassable barrier $(\mathrm{R}=10$ 000).

As our connectivity model described below necessitates 2D-maps of riverscape resistance to movement, flow velocities from MARS-3D model in subtidal zones were averaged over the water column and across each time step. The choice of taking the average value was a compromise allowing to both not underestimate the transport capacity of the tide and to dampen the potential barrier effects in the most fast-flowing areas potentially avoided by the juveniles through adjustment of their vertical position in the water column. Average flow velocities per grid cell were divided into 6 classes. The mean of each class $\mathrm{V}_{\mathrm{x}}(0.05,0.2$, $0.5,0.85,1.1,>1.2 \mathrm{~m} \mathrm{~s}^{-1}$ ) was used for the calculation of resistance values. In the intertidal areas (mudflats, tidal creeks), mean flow velocities were estimated for each tidal time step based on earlier field measurements (Online Resource 2). Current velocities below $0.05 \mathrm{~m} \mathrm{~s}^{-1}$ were assumed neutral for movement. Velocities between 0.05 and $1.2 \mathrm{~m} \mathrm{~s}^{-1}$ were assumed to facilitate movement, and resistance values $\mathrm{R}_{\mathrm{x}}$ were calculated as inversely proportional to $0.05 \mathrm{~m} \mathrm{~s}^{-1}$ (considered equivalent to neutral to movement) $\left(\mathrm{R}_{\mathrm{x}}=\mathrm{V}_{\mathrm{x}} / 0.05\right)$. We assumed that flow velocities above $1.2 \mathrm{~m} \mathrm{~s}^{-1}$ (the fourfold of the average juvenile's own speed in their first summer) would be avoided by the juveniles (due to potential risk of mortality or impingement 
by the flow) and considered them in the model as barriers $(\mathrm{R}=10000)$. Dikes, unless

322 submerged by at least $0.2 \mathrm{~m}$, were mapped as pixels out of water. Based on these principles, resistance maps were produced for each tidal time step (Figure 3).

\section{Least-cost modelling of habitat connectivity during the tide: a chronological approach}

We used ANAQUALAND (Le Pichon and others 2006) and ARCGIS 10.3 to estimate estuarine mouth connectivity to seabass nursery and refuge habitats across the estuary over the tidal cycle. ANAQUALAND requires 2D-raster maps of habitat patches and riverscape resistance to movement as input, and takes into consideration an upstream-downstream (or vice-versa) orientation of the flow direction. The software uses least-cost modelling to calculate minimum functional distance to the nearest habitat patch for each pixel of the map. To distinguish between pixels connected or not connected to a habitat of interest at a given point in time, we applied a swimming-speed-dependent threshold value or "mobility coefficient" (Roy and Le Pichon 2017) which varied depending on the tested scenario (see below). Leastcost modelling of tidal flood phase was carried out for all scenarios. Furthermore, for the lowest swimming speed scenario (see below), several complete tidal cycles were modelled. We used a chronological principle: starting from departure patches at low tide, connectivity between habitat patches was modelled over successive time steps (see Online Resource 4 for details). Only habitat patches connected to the previous step $\left(t_{N}\right)$ of the tidal cycle were taken into account for modelling each subsequent time step $\left(t_{N+1}\right)$ (Figure 4$)$. During the high tide $\left(\mathrm{t}_{14}-\mathrm{t}_{24}\right)$, we assumed a multidirectional small-scale exploratory movement between neighbouring nursery patches driven by feeding behaviour rather than further directed colonisation of the estuary in its longitudinal extent.

A sensitivity analysis was conducted to cover several levels of mobility between early spring juveniles with very weak swimming capacities $\left(0.05 \mathrm{~m} \mathrm{~s}^{-1}\right)$ and summer juveniles of up to $6 \mathrm{~cm}$ total length progressively acquiring swimming speed. The expected sustained 
swimming speed of the juveniles at the end of the first summer was calculated as a fivefold of

347 their body length per second $\left(0.6 * 5=0.3 \mathrm{~m} \mathrm{~s}^{-1}\right.$; Leis and others 2012) and was in line with the

348 ranges of optimal speeds reported for late juveniles (Claireaux and others 2006). We modelled

349 four scenarios corresponding to four swimming speeds $\left(0.05 ; 0.1 ; 0.2 ; 0.3 \mathrm{~m} \mathrm{~s}^{-1}\right)$. The

350 colonisation front for each scenario was determined as the position of the most-upstream

351 nursery habitats accessible at the beginning of the high tide.

352 To estimate the duration of complete colonisation of the estuary by early juveniles, we modelled successive tidal cycles including ebb and low tide phases for the $0.05 \mathrm{~m} \mathrm{~s}^{-1}$ scenario

354 (at both TC 52 and TC 85), until the upstream limit of the study area was reached. Starting 355 from the second tidal cycle, the refuge habitat patches accessible at the end of the previous 356 tidal cycle were used as the departure habitat of the following tide. The low tide could 357 potentially be used for further advancing the colonisation front, if the individuals restarted 358 directed movement in the upstream direction already at this tidal stage. However: i) the actual 359 behaviour of the juveniles at low tide is largely unknown; ii) the current velocities at this tidal 360 phase are very low and multidirectional; iii) the own swimming speed of the juveniles tested 361 in this scenario was very low $\left(0.05 \mathrm{~m} \mathrm{~s}^{-1}\right)$ and would allow them to advance in areas with no 362 assisting flow at most by $450 \mathrm{~m}$ over the low tide duration $(2.5 \mathrm{~h})$. Considering these uncertainties, we chose not to take potential low-tide movement into account, and assumed in

364 the model, that the position of the juveniles in the beginning of the next flood would be 365 approximately the same as in the end of the preceding ebb. 
369 Intra-annual analysis: potential nursery availability at high tide

370 Our comparison of high-tide habitat distribution across different hydrological conditions

371 showed two main trends: i) a non-linear response of potential nursery surfaces to tidal

372 coefficient gradient on both north and south sides (Figure 5a), and ii) consistent differences in

373 habitat distribution between estuarine sectors (Figure 5b). The total area of potential estuarine

374 nursery surface at high tide varied by about 80 ha across the hydrological conditions tested.

375 The extremes of potential nursery surface were found at the higher discharge level $\left(800 \mathrm{~m}^{3} \mathrm{~s}^{-}\right.$

$37{ }^{1}$ ) with the minimum of 351.3 ha at TC 115 (the highest TC tested) and the maximum of $377 \quad 434.4$ ha at TC 45 (the lowest TC tested).

378 Under all hydrological conditions, potential habitats were predominantly located in the 379 estuarine mouth area (52-70\% on the north side, and 54-87\% in the south) with the rest 380 distributed between the tidal creek sector and the intertidal zones along the channel 381 (Figure 5b). Potential habitat availability in different sectors on the north side was rather 382 stable across different hydrological conditions: it varied moderately in the mouth area, and, at 383 both discharge levels, showed a progressive increase in tidal creeks and a decrease in the 384 intertidal zones along the channel with augmenting TC (Figure 5b). On the south side, the 385 relative distribution of high-tide nurseries between the mouth area and other sectors was less 386 balanced in space and time. For instance, the surface of potential nursery habitats in the 387 mouth area decreased by over 100 ha between the lowest and the highest TC (Figure 5b).

388 Nursery availability in other sectors was considerably lower on the south side compared to the 389 north side. Only in tidal creeks did it increase along the tested TC gradient with nursery 390 surface multiplied by four between the lowest and the highest TC at both discharge levels 391 (Figure 5b). 


\section{Intra-tidal analysis: dynamics of potential nursery availability}

394 We found an even higher level of variation in potential nursery availability when zooming 395 into the dynamics of a single tidal cycle. During the tide, the distribution of potential nursery 396 habitats progressively shifted in the lateral and longitudinal direction resulting in no overlap 397 between the low-tide and the high-tide habitat patches (Figure 6). In the beginning of the 398 flow, most habitat patches were located in the downstream areas of the subtidal zone. With 399 the tidal water level rise, intertidal zones became progressively submerged and hydrologically 400 reconnected to the main channel, whereas some nursery patches in the mouth area became 401 unfavorable. This resulted in an unbalanced distribution of low-tide versus high-tide habitats 402 at the estuarine scale with high-tide "desert areas" (stretches completely lacking habitat) 403 emerging along the diked channel both on the south (downstream part) and the north (first 404 loop of the Seine) side (Figure 6). The intra-tidal decrease of the habitat surface in the mouth area was particularly 406 pronounced in the south: habitat surface available there was four to nine times lower (at TC 52 and TC 85 respectively) at high tide compared to low tide (Figure 7b). This decrease 408 was moderate in the north, where low-to-high-tide relation of habitat surface was 2:1 at both 409 TCs. Temporary loss of habitat in the mouth area was compensated by a substantial increase 410 of habitat surface in the tidal creek area (1:4 at TC 52 and 1:8 at TC 85) in the north, but not

411 in the south, where very little intertidal habitat was available throughout the tidal cycle at both 412 tidal coefficients (Figure 7b).

Tidal coefficient also affected the lateral habitat distribution and degree of

414 fragmentation. At TC 52, the lateral extent of habitats was smaller and the strips of habitat 415 patches along the diked channel upstream were more continuous, whereas, at TC 85, many of 
416 these patches became very narrow or completely unavailable due to a drastic water depth

417 increase in this area (insets in Figure 6).

418 Connectivity analysis: nursery accessibility from the estuarine mouth

419 Both tidal coefficients and fish swimming speeds tested had a strong effect on the

420 colonisation front reached within a single flood (Figure 8). Advancement in the estuary was

421 faster at the lower tidal coefficient (TC 52). With a minimal own speed of $0.05 \mathrm{~m} \mathrm{~s}^{-1}$, using

422 the upstream-directed current, the juveniles would reach the areas above the largest tidal creek

423 on the north side within a single tide (Figure 8a). Increasing swimming capacity advanced

424 their colonisation front progressively on both the north and the south side, with an average

425 gain of $9.4 \mathrm{~km}$ (along the shoreline) with every $0.1 \mathrm{~m} \mathrm{~s}^{-1}$ of own speed added. The swimming

426 speed of $0.3 \mathrm{~m} \mathrm{~s}^{-1}$ resulted sufficient for colonising the whole estuary within a single flood.

427 At the higher tidal coefficient (TC 85), not only did the colonisation front advance

428 substantially slower compared to TC 52 in each of the swimming speed scenarios, but also the

429 extent of this difference varied depending on the side of the estuary. Thus, while on the north

430 side, the colonisation front of the $0.05 \mathrm{~m} \mathrm{~s}^{-1}$ was situated $3.4 \mathrm{~km}$ further downstream

431 compared to the same scenario at TC 52, on the south side, this gap was about three times

432 larger (Figure 8). It is only for the swimming speed of $0.2 \mathrm{~m} \mathrm{~s}^{-1}$, that colonisation fronts at TC

43385 became approximately aligned between the north and the south side (Figure 8b). Finally, at

434 TC 85, the full extent of the estuary could not be colonised within a single tidal cycle in the

$4350.3 \mathrm{~m} \mathrm{~s}^{-1}$ scenario: $1.8 \mathrm{~km}$ and $3.7 \mathrm{~km}$ remained until the upstream limit of the study area on

436 the north and south side respectively.

437 Importantly, while increasing juvenile swimming speed accelerated upstream

438 advancement of the colonisation front, the effective gain in total accessible habitat surface

439 was very moderate. The number of habitat patches reached at high tide was multiplied by two 
440 (TC 52) and four (TC 85) between the lowest and the highest swimming speed scenarios, but 441 this corresponded to only $30 \%$ increase of the total habitat surface accessible across the 442 estuary (Supplementary Figure S4). This result was consistent with the general pattern of

443 habitat fragmentation along the estuary with large habitat patches available in the mouth area 444 and a high number of smaller habitat patches present in the upstream areas (Figure 6). particularly evident when modelling progressive colonisation of the estuary at the lowest swimming speed $\left(0.05 \mathrm{~m} \mathrm{~s}^{-1}\right)$. The full colonisation of the estuary necessitated five tidal cycles at TC 52 and seven cycles at TC 85 . Even if at both TCs the mouth areas of some of the largest tidal creeks were reached rapidly, a second tidal cycle appeared necessary for full 450 colonisation of the lateral dimension (inset in Figure 9). As mentioned above, this result did not take into account that some further advancement in the creek could have eventually been made during the high tide of the first tidal. bottlenecks for weak dispersers. In particular, local connectivity disruptions behind the colonisation front were observed at some stages of the flood in the first loop of the Seine

456 (Supplementary Figure S5). Fish that would have advanced above this area in the beginning of the flood would remain in an area disconnected from downstream habitat patches at later 458 stages of the flood.

\section{Discussion}

460 The term "moving target" has been coined in conservation biology to underline the 461 importance of considering habitat patch dynamics tracked by animal movement for 462 establishing meaningful measures of protection (Bull and others 2013). Highly dynamic

463 environments represent a challenge for understanding and quantifying patterns of habitat 
availability, especially, because not only the structure (patch size and distribution), but also

465 functional connectivity of such landscapes varies in space and time (Zeigler and Fagan 2014).

466 Characterised by pronounced spatial dynamics of habitat turnover and connectivity at several

467 temporal scales, macrotidal estuaries are perfect examples of environments with constantly

468 "moving targets".

Previous studies have mapped large-scale nursery availability (Nagelkerken and others

2015; Whaley and others 2007), and emphasised the paramount importance of the intrahabitat connectivity for the value of estuarine and coastal nurseries (Secor and Rooker 2005; estuarine habitat availability. Trapping and video observations during flood and ebb tides recorded the transient habitat utilization by young stages of many necton species (Bretsch and Allen 2006; Ellis and Bell 2008; Laffaille and others 2001). However, technically challenging, such field studies are limited in spatial scale and temporal resolution. Spatiotemporally explicit approaches, which integrate hydrological and biotic connectivity of a landscape, appear indispensable for quantifying habitat dynamics and accessibility in large estuaries. Our study represents, to our knowledge, the first case of least-cost modelling

480 application to estuarine habitats and the first example of investigating intra-tidal habitat dynamics across a large estuary with such a fine spatio-temporal resolution.

483 In the pristine Seine estuary (large, shallow, and with weak lateral slopes), water level 484 increase during the tidal cycle must have led to a continuous shifting of shallow areas from 485 mudflats in the mouth area into tidal creeks and salt marshes (lateral shifts) as well as in the 486 upstream direction (longitudinal shifts). In these conditions, seabass juveniles probably had 487 access to nurseries throughout the tidal cycle and at any hydrological conditions. We observe 
no spatio-temporally continuous access to shallow-water nurseries across the Seine estuary in

489 its current highly modified state. Altogether, we find a highly counter-intuitive result: the 490 relationship between water level and potential nursery surface availability is inversed. Thus,

491 in contrast to what we would expect in a pristine system, in the modern Seine estuary,

492 advancing tidal flow results in a dramatic drop of the total nursery habitat surface. This is

493 particularly pronounced on its south side, where temporary gaps in nursery distribution

494 emerge.

Highly modified topography of the Seine estuary is the most likely explanation for this "surprise", and this conclusion is in line with previous studies of artificialised floodplains of

497 the upstream Seine river (Le Pichon and others 2009) and the Saint-Lawrence River (Foubert 498 and others 2019). Harbour expansion, channel dredging, and creation of steep banks along 499 submersible dikes led to a massive loss of the intertidal zones (Cuvilliez and others 2009), and 500 introduced artificial «breaks » in the cross-sectional profile of the estuary (Supplementary 501 Figure S6). Consequently, in many areas of the mouth zone, no gradual transition between the 502 subtidal and the intertidal zones exists anymore. Instead, with the rising water level, shallow 503 patches get fragmented and small, and, at some point, disappear locally until a critical water 504 level allowing for dike submersion is reached, and the intertidal zones behind them become 505 available for colonisation. Dike construction and channel dredging have also modified the 506 estuarine permeability to movement. Our results show that flow velocities along the dikes 507 increase substantially during the tide. At some stages of the tide, channel current velocities are 508 so high that juvenile movement may only be possible in remaining narrow strips of slow flow 509 velocity along the channel margins.

510 The role of dispersal capacity for estuarine colonisation 
511 In order to predict an organism's propagation through a landscape, we need to consider its

512 dispersal capacity and behaviour in interaction with the environment it encounters. In a

513 riverscape, the extent of fish movement is predominantly determined by the animal's

514 swimming capacity, the flow velocities, and the direction of the current. Behavioural

515 strategies of marine and estuarine fish, such as selective tidal transport, allow them to

516 augment movement range and reduce related energy costs in systems exposed to tides and

517 current reversal (Forward and Tankersley 2001). Here, testing several scenarios allowed us to

518 analyse the effects of swimming speed on the estuarine colonisation using selective tidal

519 transport. We show that, early juveniles with a low swimming capacity need several

520 successive tides to reach high-tide nurseries in the entire study area, while a single tide would

521 be sufficient by the end of their first summer.

522 Our results, representative of hydrological conditions at medium discharge $\left(250 \mathrm{~m}^{3} . \mathrm{s}^{-}\right.$

$523^{1}$ ), suggest that colonisation is facilitated by low rather than by high TCs. On the occasion of

524 spring flooding, extreme river discharge levels (potential triggers of estuarine colonisation;

525 Jennings and Pawson 1992) may occur in the Seine estuary, whereby tidal flood current

526 velocities are counteracted by the river discharge (unpublished simulations of MARS-3D

527 model, Lemoine). This effect, which we, unfortunately, could not explore in the framework of

528 this study, should probably reduce both the speed of juvenile advancement in the estuary and

529 the extent of estuarine areas with high currents and thus the potential risk of being swept away

530 at high TCs.

$531 \quad$ Altogether, our comparison across different steps of the tidal cycle allows for several

532 conclusions. We show that transient local bottlenecks of nursery availability and accessibility

533 emerge in the Seine estuary during specific time windows of the tidal cycle. Our second

534 conclusion is that these bottlenecks are driven both by progressive habitat fragmentation and

535 by locally increasing riverscape resistance to movement. Finally, own mobility of juveniles 
appears to play a key role for successful colonisation with weak dispersers obliged to follow a stepping-stone-type colonisation.

\section{Caveats and limitations of least-cost analysis}

540 Chronological modelling approach, proposed here for dynamic environments, requires a

541 careful consideration of the choice of appropriate spatio-temporal scales. The latter should

542 cover the range of variation in both habitat availability and connectivity relevant for the

543 movement of the species with its specific ecological, behavioural and dispersal-related traits.

544 In the case of the seabass juvenile estuarine colonisation, the spatial component had to include

545 both an extent sufficient for covering the entire area of the estuarine mouth containing tidal

546 habitats, and a resolution allowing us to consider narrow tidal creeks and channel banks with

547 high-tide nurseries. Furthermore, the selection of time steps had to capture the structural

548 connectivity changes during the tidal cycle. Remote sensing data and a 2D-hydrodynamic

549 model available for the Seine estuary at high spatio-temporal resolution permitted us to fulfill

550 these criteria.

While our approach provides a highly flexible and spatially relevant framework, some

552 limitations related to biological assumptions and their translation into habitat and connectivity

553 modelling exist. Thus modelled nursery habitat was primarily defined by a combination of

554 water depth ranges and sediment characteristics established based on rare reported field

555 observations of juvenile seabass in the intertidal zones of NEA coast. Ideally, fine-scale field

556 investigations of nursery habitat characteristics, potentially taking into account further

557 dynamic variables (e.g. turbidity, temperature, dissolved oxygen or food availability) would

558 allow for a better delimitation of nursery habitats. Furthermore, in the connectivity analysis

559 applied we could not consider differences in habitat quality and patch size, which could affect

560 patch carrying capacity and juvenile preferences (Teichert and others 2018). 
562 Resistance values attributed to each pixel of a riverscape map are a crucial element linking

563 GIS-based data to the organism mobility and dispersal behaviour (Adriaensen and others

564 2003). Field or mesocosm studies quantifying the effect of high current velocities on early

565 juvenile fish could improve the calibration of riverscape resistance to movement and the

566 precision of the current velocity threshold above which water flow may become a barrier.

567 Further sensitivity analysis may allow for quantification of the effects of these parameters and 568 the related error margins (Beier and others 2008). However, in the case of complex

569 chronological calculations as the ones presented here, investigating ranges of values is rapidly

570 translated into long computation times and a compromise needs to be found. Here we chose to

571 focus on testing a plausible range of juvenile seabass mobility parameters.

\section{Implications for management and conservation}

573 Fish stocks of many marine and estuarine species experience a drastic decline (Christensen 574 and others 2014; Vasilakopoulos and others 2014). Increasing attention has been given in the 575 last decades to identifying population bottlenecks, notably at the sensitive stages of spawning, 576 juvenile colonisation of nurseries and growth, to be targeted by management and conservation 577 efforts (Sheaves and others 2015). In macrotidal estuaries, the nature and drivers of such 578 bottlenecks may be difficult to identify and common-sense assumptions (as simple as "higher 579 water level means more available intertidal habitat") may prove to be misleading in human580 modified systems.

$581 \quad$ Chronological functional connectivity modelling offers a road for addressing this 582 challenge. Zooming into the processes occurring during tidal cycles helps disentangle the 583 effects of habitat fragmentation and riverscape connectivity and identify the timing of 584 occurrence and location of the transient bottlenecks that may affect habitat colonisation by 
585 juveniles. Maps produced by our approach may be directly used to test and visualize the

586 consequences of different management scenarios, and subsequently guide decision-making

587 (e.g. prioritisation of areas for dike removal or for conservation).

588 Our work demonstrates that focusing exclusively on the protection and restoration of

589 high tide nurseries may prove inefficient, as they may be disconnected from the succession of

590 habitat patches needed over the tidal cycle. This is an empirical illustration to the notions of

591 "moving targets" (Bull and others 2013), "seascape nurseries" (mosaics of functionally

592 connected habitat patches; Nagelkerken and others 2015) and "transient windows for

593 connectivity" (Zeigler and Fagan 2014) formulated in conservation biology and emphasising

594 the importance of taking the mobile nature of connectivity and habitats into account when

595 planning conservation measures. We suggest that chronological functional connectivity

596 modelling is a valuable tool applicable to any ecosystem where organisms have to cope with

597 highly dynamic environments over their life cycle.

598

\section{Acknowledgments}

600 This study has been carried out in the framework of the ANACONDHA project funded by the

601 scientific research program of the GIP Seine-Aval. We cordially thank Nicolas Bacq for his

602 invaluable support, ideas and work orientations throughout the project, Sylvain Duhamel, Eric

603 Feunteun, Ronan Le Goff, Mike Pawson, Hélène de Pontual, Florian Rozanska and Stéphanie

604 Moussard for sharing their expertise and time during fruitful discussions at different stages of

605 this project, Jean-Philippe Lemoine for producing MARS-3D model outputs, Eric L'Ebrellec

606 for preparing habitat and water depth maps and providing supplementary data on the Seine

607 estuary, Sylvain Descloux for his support with improving ANAQUALAND, and Amandine

608 Zahm for running part of the tested scenarios. We kindly thank two anonymous reviewers and 
609 the editors for their very constructive and insightful comments that helped to substantially

610 improve the manuscript throughout the revision process. 


\section{References}

612 Adriaensen F, Chardon JP, De Blust G, Swinnen E, Villalba S, Gulinck H, Matthysen E. 2003. The application of 'least-cost' modelling as a functional landscape model. Landsc Urb Plan 64:233-247.

Avoine J, Allen GP, Nichols M, Salomon JC, Larsonneur C. 1981. Suspended-sediment transport in the Seine estuary, France: Effect of man-made modifications on estuaryshelf sedimentology. Mar Geol 40:119-137.

Baguette M, Blanchet S, Legrand D, Stevens VM, Turlure C. 2013. Individual dispersal, landscape connectivity and ecological networks. Biol Rev 88:310-326.

Beier P, Majka DR, Spencer WD. 2008. Forks in the road: choices in procedures for designing wildland linkages. Conserv Biol 22:836-851.

Bretsch K, Allen DM. 2006. Tidal migrations of nekton in salt marsh intertidal creeks. Estuaries Coast 29:474-486.

Bull JW, Suttle KB, Singh NJ, Milner-Gulland E. 2013. Conservation when nothing stands still: moving targets and biodiversity offsets. Front Ecol Environ 11:203-210.

Cabral H, Costa MJ. 2001. Abundance, feeding ecology and growth of 0-group sea bass,

Caldwell I, Gergel S. 2013. Thresholds in seascape connectivity: influence of mobility, Dicentrarchus labrax, within the nursery areas of the Tagus estuary. J Mar Biol Assoc UK 81: 679-682. habitat distribution, and current strength on fish movement. Landsc Ecol 28:1937-1948.

Capra H, Plichard L, Bergé J, Pella H, Ovidio M, McNeil E, Lamouroux N. 2017. Fish habitat 635 selection in a large hydropeaking river: Strong individual and temporal variations revealed by telemetry. Sci Tot Environ 578:109-120.

Carbonneau P, Piégay H. 2012. Fluvial remote sensing for science and management. John Wiley \& Sons. 
636 Cattrijsse A, Makwaia ES, Dankwa HR, Hamerlynck O, Hemminga MA. 1994. Nekton communities of an intertidal creek of a European estuarine brackish marsh. Mar Ecol Progr Ser 109: 195-208.

639 Cattrijsse A, Hampel H. 2006. European intertidal marshes: a review of their habitat 640 functioning and value for aquatic organisms. Mar Ecol Prog Ser 324: 293-307.

641 Christensen V, Coll M, Piroddi C, Steenbeek J, Buszowski J, Pauly D. 2014. A century of 642 fish biomass decline in the ocean. Mar Ecol Prog Ser 512: 155-166.

643 Claireaux G, Couturier C, Groison A-L. 2006. Effect of temperature on maximum swimming 644 speed and cost of transport in juvenile European sea bass (Dicentrarchus labrax). J Exp $645 \quad$ Biol 209:3420-3428.

646 Cuvilliez A, Deloffre J, Lafite R, Bessineton C. 2009. Morphological responses of an 647 estuarine intertidal mudflat to constructions since 1978 to 2005: The Seine estuary (France). Geomorphology 104:165-174.

Ellis WL, Bell SS. 2008. Tidal influence on a fringing mangrove intertidal fish community as observed by in situ video recording: implications for studies of tidally migrating nekton. Mar Ecol Prog Ser 370:207-219.

652 Fahrig L. 1992. Relative importance of spatial and temporal scales in a patchy environment. Theor Popul Biol 41:300-314.

654 Forward RB, Tankersley RA. 2001. Selective tidal-stream transport of marine animals. Oceanogr Mar Biol 39:305-353.

656 Foubert A, Le Pichon C, Mingelbier M, Farrell JM, Morin J, Lecomte F. 2019. Modeling the 657 effective spawning and nursery habitats of northern pike within a large spatiotemporally variable river landscape (St. Lawrence River, Canada). Limnol Oceanogr 64:803-819. 

morphologique d'un estuaire anthropisé de 1800 à nos jours. Fascicule Seine-Aval 2.3. https://www.seine-aval.fr/publication/fasc-evolution-morphologique/

Fritsch M. 2005. Traits biologiques et exploitation du bar commun Dicentrarchus labrax (L.) dans les pêcheries françaises de la manche et du golfe de Gascogne. Doctoral dissertation, University of Western Brittany.

Gibson RN. 2003. Go with the flow: tidal migration in marine animals. Hydrobiologia 503:153-161.

Grasso F, Le Hir P. 2019. Influence of morphological changes on suspended sediment dynamics in a macrotidal estuary: diachronic analysis in the Seine Estuary (France) from 1960 to 2010. Ocean Dyn 69:83-100.

Green BC, Smith DJ, Grey J, Underwood GJ. 2012. High site fidelity and low site connectivity in temperate salt marsh fish populations: a stable isotope approach. Oecologia 168:245-255.

Hanke MH, Lambert JD, Smith KJ. 2014 Utilization of a multicriteria least-cost path model in an aquatic environment. Int J Geogr Inf Sci 28:1642-1657.

Hohensinner S, Jungwirth M, Muhar S, Schmutz S. 2011. Spatio-temporal habitat dynamics in a changing Danube River landscape 1812-2006. Riv Res Appl 27:939-955.

677 Jennings S, Lancaster JE, Ryland JS, Shackley SE. 1991. The age structure and growth dynamics of young-of-the-year bass, Dicentrarchus labrax, populations. J Mar Biol

Jennings S, Pawson M. 1992. The origin and recruitment of bass, Dicentrarchus labrax, larvae to nursery areas. J Mar Biol Assoc UK 72:199-212. 464. 
684 Kelley D. 2002. Abundance, growth and first-winter survival of young bass in nurseries of 685 south-west England. J Mar Biol Assoc UK 82:307-19.

Keymer JE, Marquet PA, Velasco-Hernández JX, Levin SA. 2000. Extinction thresholds and metapopulation persistence in dynamic landscapes. Am Nat 156:478-494.

Laffaille P, Lefeuvre J-C, Schricke M-T, Feunteun E. 2001. Feeding ecology of o-group sea bass, Dicentrarchus labrax, in salt marshes of Mont Saint Michel Bay (France). Estuaries 24:116-125.

Lafite R, Romaña L-A. 2001. A man-altered macrotidal estuary: the Seine estuary (France): introduction to the special issue. Estuaries Coast 24:939-939.

Le Hir P, Lafite R. 2012. Projet MODEL: Modélisation validée de l'hydro-morphosédimentologie, base physique d'une modélisation environnementale de l'estuaire de la Seine. GIP Seine Aval https://www.seine-aval.fr/projet/model/

Le Pichon C, Gorges G, Baudry J, Goreaud F, Boët P. 2009. Spatial metrics and methods for riverscapes: quantifying variability in riverine fish habitat patterns. Environmetrics 20:512-526.

Le Pichon C, Gorges G, Faure T, Boussard H. 2006. Anaqualand 2.0: freeware of distances calculations with frictions on a corridor. 2.0 edn. Cemagref, Antony https://www6.rennes.inra.fr/sad/Outils-Produits/Outils-informatiques/Anaqualand.

Leis JM, Balma P, Ricoux R, Galzin R. 2012. Ontogeny of swimming ability in the European sea bass, Dicentrarchus labrax (L.)(Teleostei: Moronidae) Mar Biol Re. 8:265-72.

Lesourd S, Lesueur P, Fisson C, Dauvin J-C. 2016. Sediment evolution in the mouth of the Seine estuary (France): A long-term monitoring during the last 150 years. CR Geosci 348:442-450. 
López R, de Pontual H, Bertignac M, Mahévas S. 2015. What can exploratory modelling tell us about the ecobiology of European sea bass (Dicentrarchus labrax): a comprehensive overview. Aquat Living Resour 28:61-79.

Lotze HK, Lenihan HS, Bourque BJ, Bradbury RH, Cooke RG, Kay MC, Kidwell SM, Kirby, MX, Peterson CH, Jackson JBC. 2006. Depletion, degradation, and recovery potential of estuaries and coastal seas. Science, 312:1806-1809.

Martinho F, Leitão R, Neto JM, Cabral H, Lagardère F, Pardal MA. 2008. Estuarine colonization, population structure and nursery functioning for 0-group sea bass (Dicentrarchus labrax), flounder (Platichthys flesus) and sole (Solea solea) in a mesotidal temperate estuary. J App Ichthyol 24:229-237.

Nagelkerken I, Sheaves M, Baker R, Connolly RM. 2015. The seascape nursery: a novel spatial approach to identify and manage nurseries for coastal marine fauna. Fish Fish $16: 362-371$

Neumann W, Martinuzzi S, Estes AB, Pidgeon AM, Dettki H, Ericsson G, Radeloff VC. 2015. Opportunities for the application of advanced remotely-sensed data in ecological studies of terrestrial animal movement. Mov Ecol 3:8.

Pastoureaud A. 1991. Influence of starvation at low temperatures on utilization of energy reserves, appetite recovery and growth character in sea bass, Dicentrarchus labrax. Aquac 99:167-178.

Pickett GD, Pawson MG. 1994. Sea bass. Biology, exploitation and conservation. Chapman \& Hall.

Ray N, Lehmann A, Joly P. 2002. Modeling spatial distribution of amphibian populations: a GIS approach based on habitat matrix permeability. Biodivers Conserv 11:2143-2165. 
Rochette S, Rivot E, Morin J, Mackinson S, Riou P, Le Pape O. 2010. Effect of nursery habitat degradation on flatfish population: Application to Solea solea in the Eastern Channel (Western Europe). J Sea Res 64:34-44.

Rouget M, Cowling RM, Lombard AT, Knight AT, Kerley GIH. 2006. Designing large-scale conservation corridors for pattern and process. Conserv Biol 20:549-561.

Rountree RA, Able KW. 2007. Spatial and temporal habitat use patterns for salt marsh nekton: implications for ecological functions. Aquat Ecol 41:25-45.

Roy ML, Le Pichon C. 2017. Modelling functional fish habitat connectivity in rivers: A case study for prioritizing restoration actions targeting brown trout. Aquat Conserv 27:927937.

Schlosser IJ. 1995. Critical landscape attributes that influence fish population dynamics in headwater streams. Hydrobiologia 303:71-81.

Secor H, Rooker JR. 2005. Connectivity in the life histories of fishes that use estuaries. Estuar Coast Shelf Sci 64:1-3.

Selleslagh J, Amara R. 2008. Environmental factors structuring fish composition and assemblages in a small macrotidal estuary (eastern English Channel). Estuar Coast Shelf Sci 79:507-517.

Sheaves M. 2009. Consequences of ecological connectivity: the coastal ecosystem mosaic. Mat Ecol Prog Ser 391:107-115.

Sheaves M, Baker R, Nagelkerken I, Connolly RM. 2015. True value of estuarine and coastal nurseries for fish: incorporating complexity and dynamics. Estuaries Coast 38:401-414.

751 Stanford JA, Lorang MS, Hauer FR. 2005. The shifting habitat mosaic of river ecosystems. SIL Proc 29:123-136; 
Sutcliffe OL, Bakkestuen V, Fry G, Stabbetorp OE. 2003. Modelling the benefits of farmland restoration: methodology and application to butterfly movement. Landsc Urban Plan $63: 15-31$

Taylor PD, Fahrig L, Henein K, Merriam G. 1993. Connectivity is a vital element of landscape structure. Oikos 68:571-573.

Tecchio S, Chaalali A, Raoux A, Tous Rius A, Lequesne J, Girardin V, Lassalle G, Cachera M, Riou P, Lobry J, Dauvin J-C, Niquil N. 2016. Evaluating ecosystem-level anthropogenic impacts in a stressed transitional environment: The case of the Seine estuary. Ecol Indic 61:833-845.

Teichert N, Carassou L, Sahraoui Y, Lobry J, Lepage M. 2018. Influence of intertidal seascape on the functional structure of fish assemblages: Implications for habitat conservation in estuarine ecosystems. Aquat Conserv 28:798-809.

Tonolla D, Acuña V, Uehlinger U, Frank T, Tockner K. 2010. Thermal heterogeneity in river floodplains. Ecosyst 13:727-740.

Vasilakopoulos P., Maravelias CD, Tserpes G. 2014. The alarming decline of Mediterranean fish stocks. Curr Biol, 24: 1643-1648.

Whaley SD, Burd Jr JJ, Robertson BA. 2007. Using estuarine landscape structure to model distribution patterns in nekton communities and in juveniles of fishery species. Mar Ecol Progr Ser 330:83-99.

Wiens JA. 1976. Population responses to patchy environments. Ann Rev Ecol Syst 7:81-120.

Wimberly MC. 2006. Species dynamics in disturbed landscapes: when does a shifting habitat mosaic enhance connectivity? Landsc Ecol 21: 35-46.

Zeigler SL, Fagan WF. 2014. Transient windows for connectivity in a changing world. Mov Ecol 2:1. 
777 Zeller KA, McGarigal K, Whiteley AR. 2012. Estimating landscape resistance to movement: a review. Landsc Ecol 27:777-797. 
780 Figure 1: A life cycle example (inspired by Schlosser 1995) with (a) living space (all

781 habitats) occupied by each stage; (b) example of directed daily movements (e.g. tidal

782 dynamics) of a single stage between habitats; (c) seasonal dynamics of habitat use of another 783 life stage (adult). $\mathrm{t}_{\mathrm{N} . . .} \mathrm{t}_{\mathrm{N}+\mathrm{i}}$ represent points in time, whereby time scales may vary.

785 Figure 2: The spatial extent of the Seine estuary considered in this study. High-tide wetted area at TC 85 (at $250 \mathrm{~m}^{3} \mathrm{~s}^{-1}$ ) is presented for 2010. Historical estuarine data is based on the maps of Magin and Magin (1750).

Figure 3: Time-step-specific resistance maps used for modelling upstream movement of 790 juveniles with the flood (two TCs and discharge of $250 \mathrm{~m}^{3} \mathrm{~s}^{-1}$ ). Colours represent resistance values $(\mathrm{R})$ calculated based on mean current velocities $(\mathrm{V})$.

Figure 4: The principle of habitat patch connectivity calculation between tidal time steps. $\mathrm{H}\left(\mathrm{t}_{\mathrm{N}}\right)$ represents departure habitat at time point $\mathrm{t}_{\mathrm{N}} ; \mathrm{H}\left(\mathrm{t}_{\mathrm{N}+1}\right)$ represent patches of potentially available habitat at the next time point $t_{\mathrm{N}+1}$. The dotted lines delineate the areas within threshold functional distances calculated with the least-cost modelling for four hypothetical scenarios. In scenario 4 , only the part of $\mathrm{H}\left(\mathrm{t}_{\mathrm{N}+1}\right)$ in light grey is connected to $\mathrm{H}\left(\mathrm{t}_{\mathrm{N}}\right)$ and retained for the next step of the analysis.

800 Figure 5: Intra-annual analysis: high-tide nursery surface areas at four TCs and two levels of 801 discharge on the north and south side: a) total potential nursery area; b) potential nursery area 802 by estuarine sector. 
804 Figure 6: Distribution of nursery habitats in the beginning and at the end of the flood at two

805 TCs and discharge of $250 \mathrm{~m}^{3} \mathrm{~s}^{-1}$.

806

807 Figure 7: Nursery surface change during the flood at two TCs and discharge of $250 \mathrm{~m}^{3} \mathrm{~s}^{-1}:$ a)

808 total potential nursery area; b) potential nursery area by estuarine sector.

809

810 Figure 8: Colonisation front under different swimming speed scenarios at two TCs and

811 discharge of $250 \mathrm{~m}^{3} \mathrm{~s}^{-1}$. Separate arrows are shown for the south and the north, when

812 colonisation fronts on the two sides are not aligned.

813

814 Figure 9: Successive tidal colonisation fronts modelled at two TCs and discharge of $250 \mathrm{~m}^{3} \mathrm{~s}^{-}$

$815{ }^{1}$ for the $0.05 \mathrm{~m} \mathrm{~s}^{-1}$ swimming speed scenario. The inset (b) shows details of the lateral

816 intertidal zones colonised at TC 52 with the first tide. Separate arrows are shown for the south

817 and the north, when colonisation fronts on the two sides are not aligned. 
Figures

819

$82 \uparrow \quad$ Figure 1

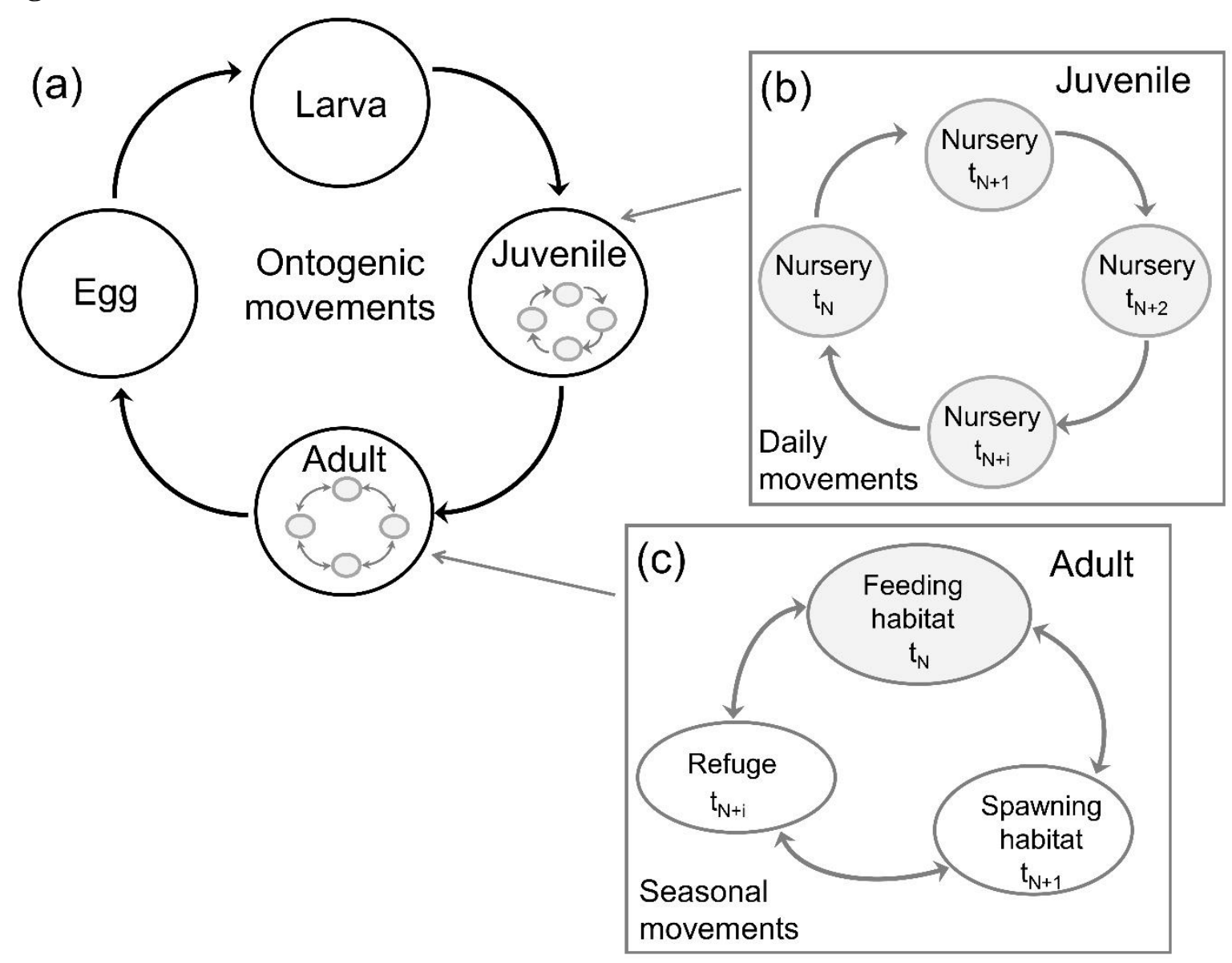




\section{$824 \quad$ Figure 2}

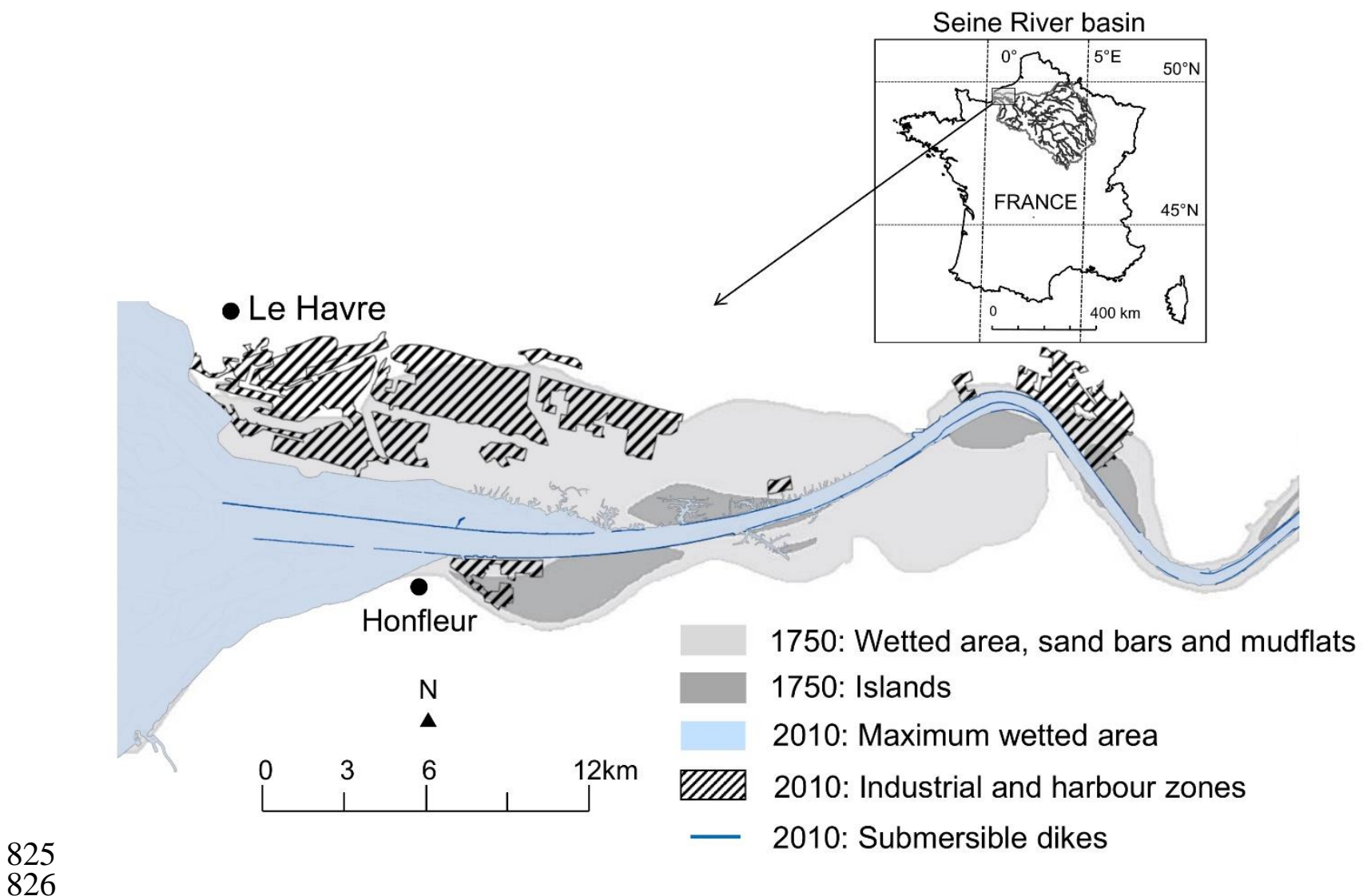

826 


\section{Figure 3}

(a) TC 52
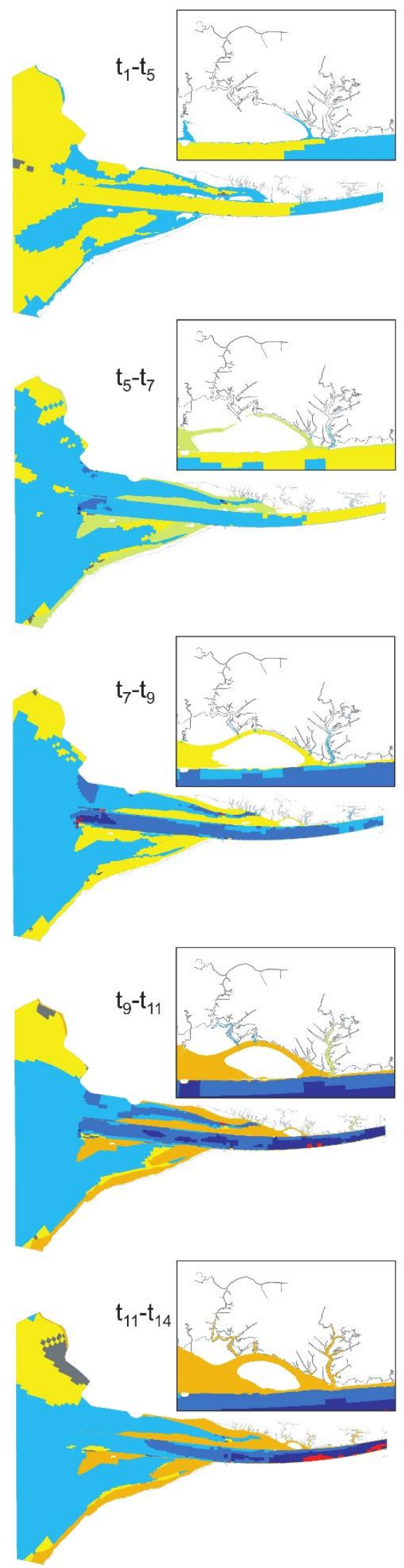

(b) TC 85

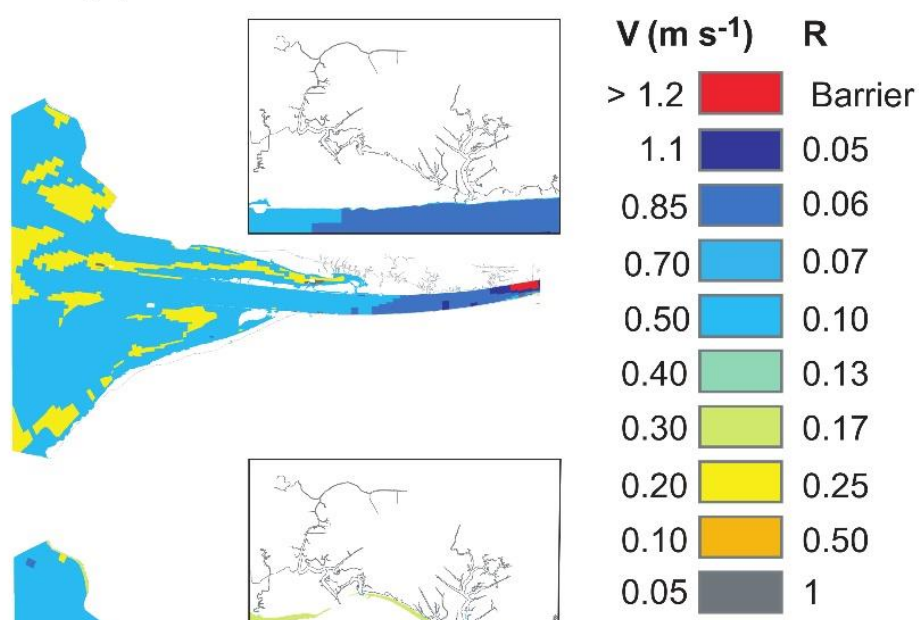

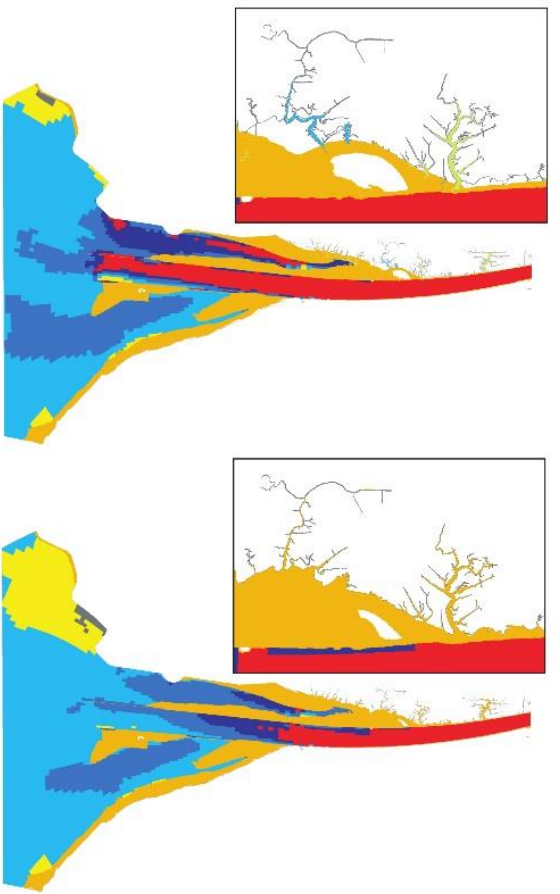


$829 \quad$ Figure 4

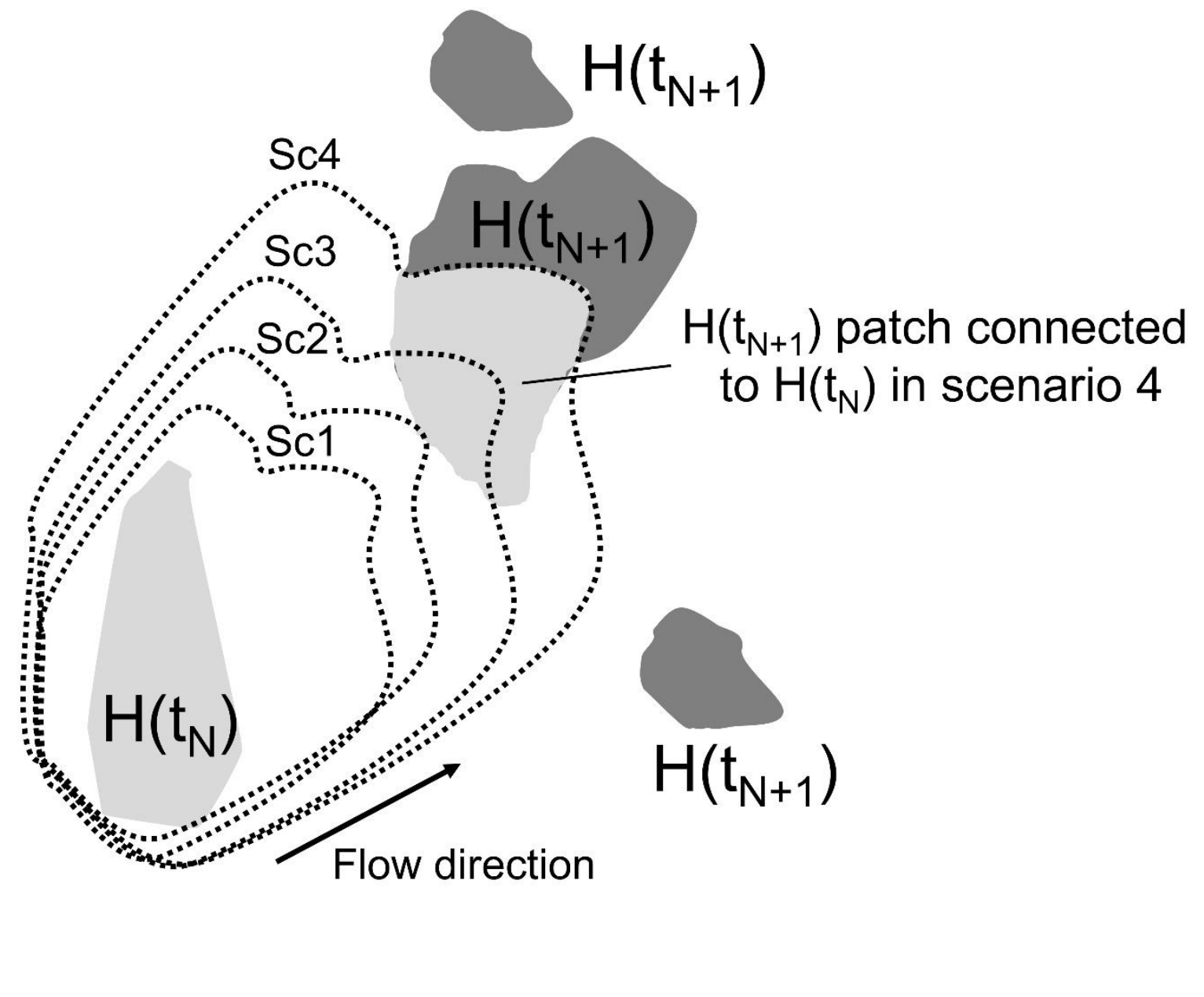



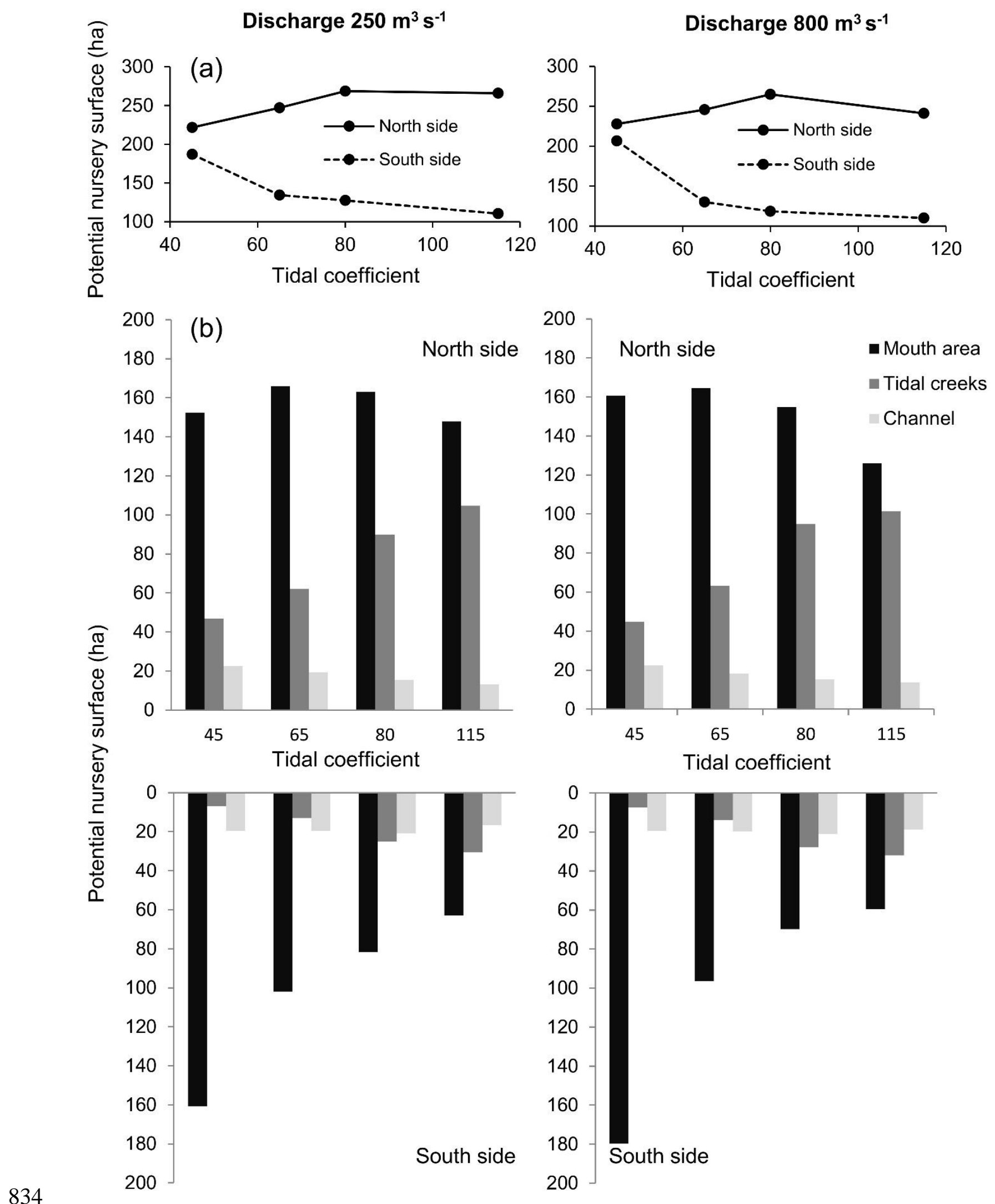
$836 \quad$ Figure 6

(a) TC 52

(b) TC 85

Nursery habitat

$60 \mathrm{~min}$

195 min

High tide " deserts »
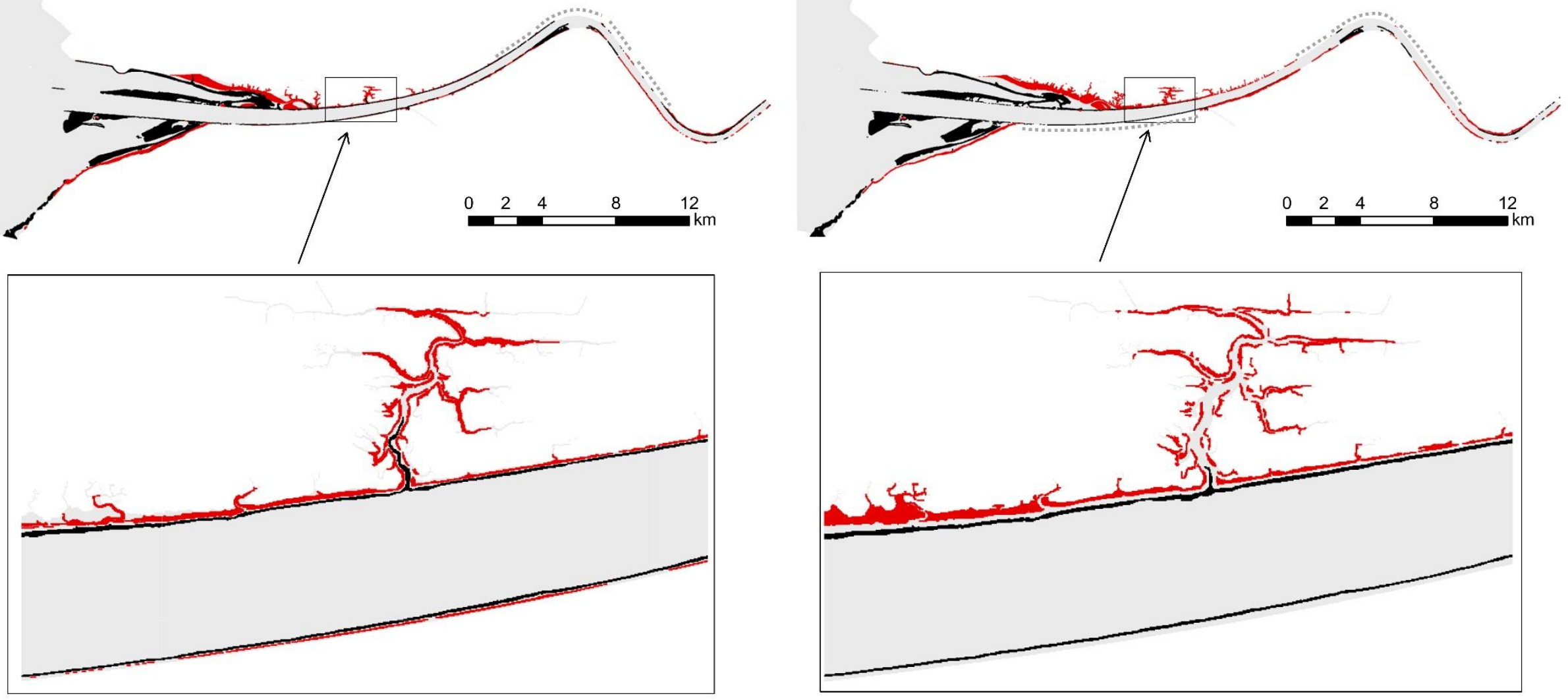

837
838

839

43 
Figure 7

TC 52

TC 85

(a)
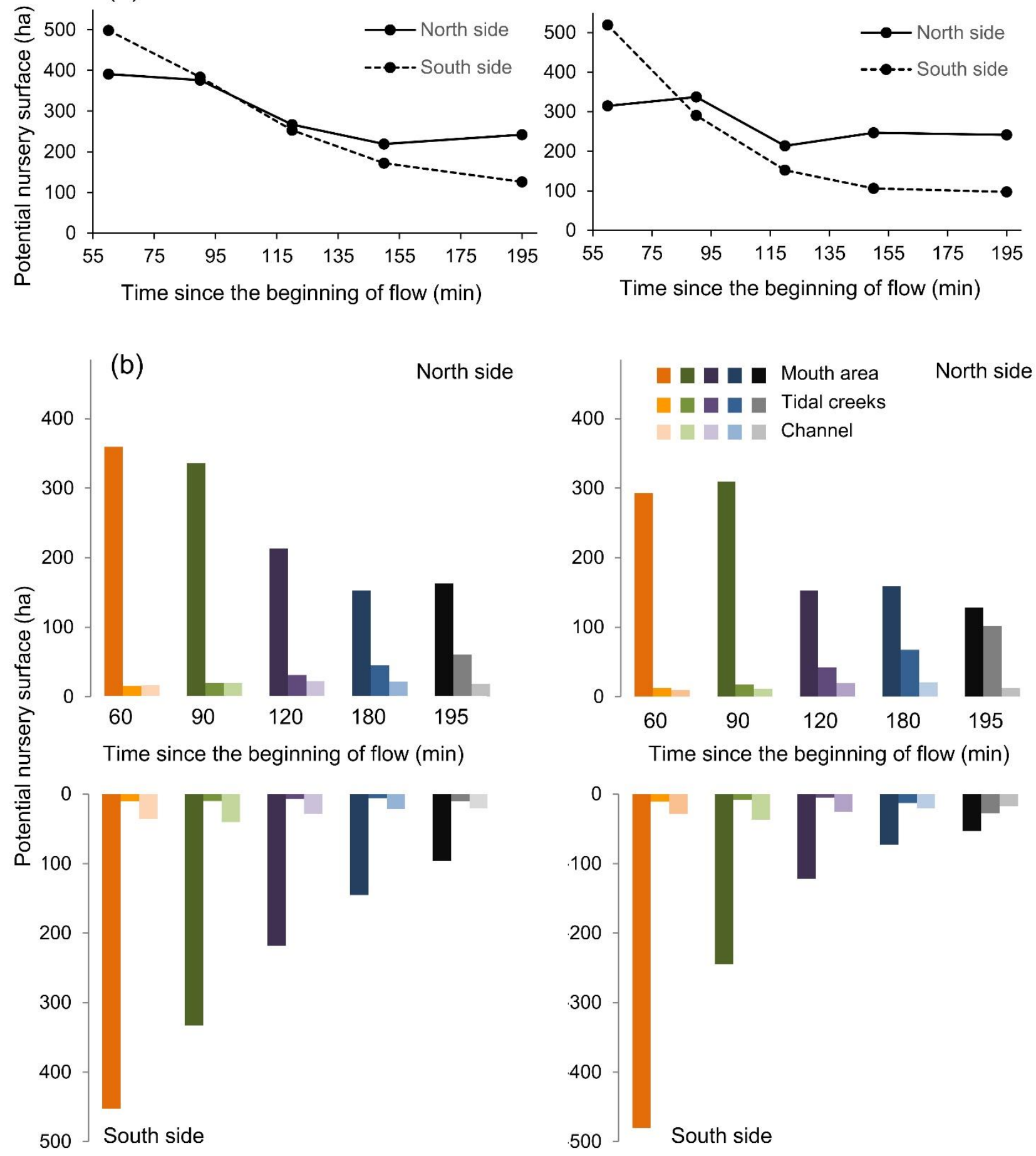
Figure 8

(a) TC 52

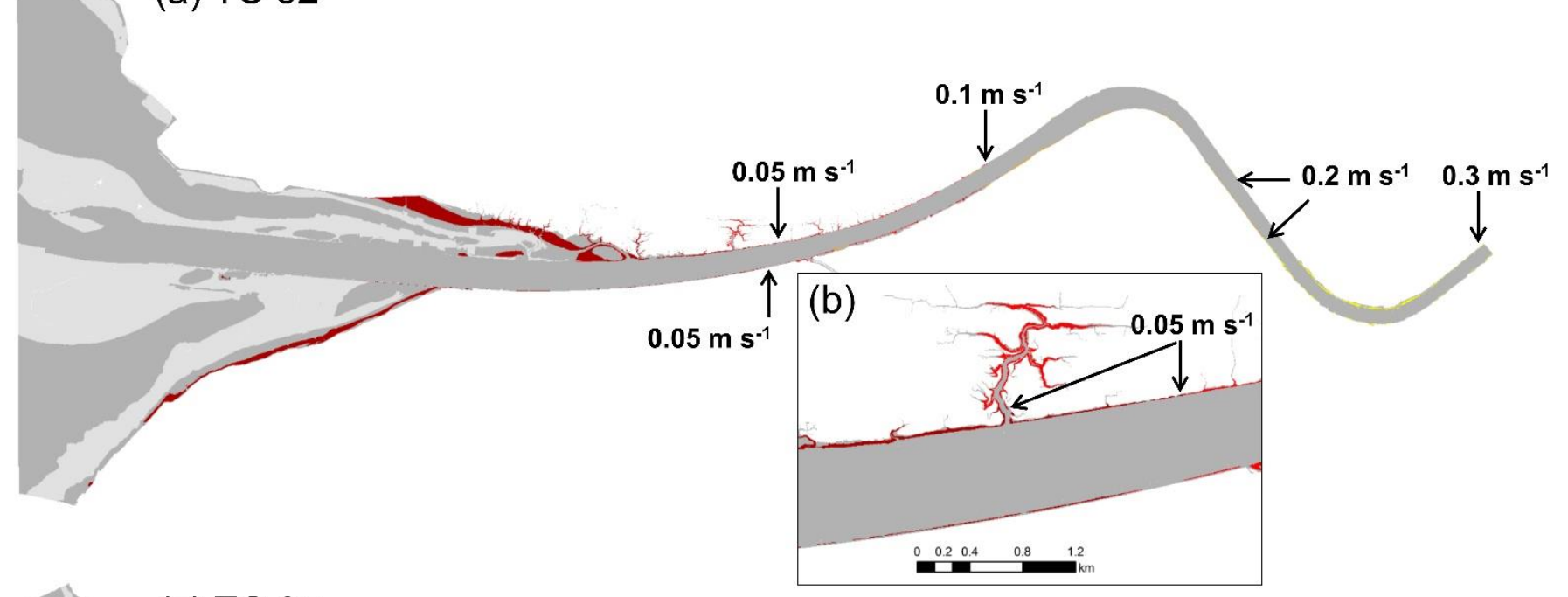

(c) TC 85

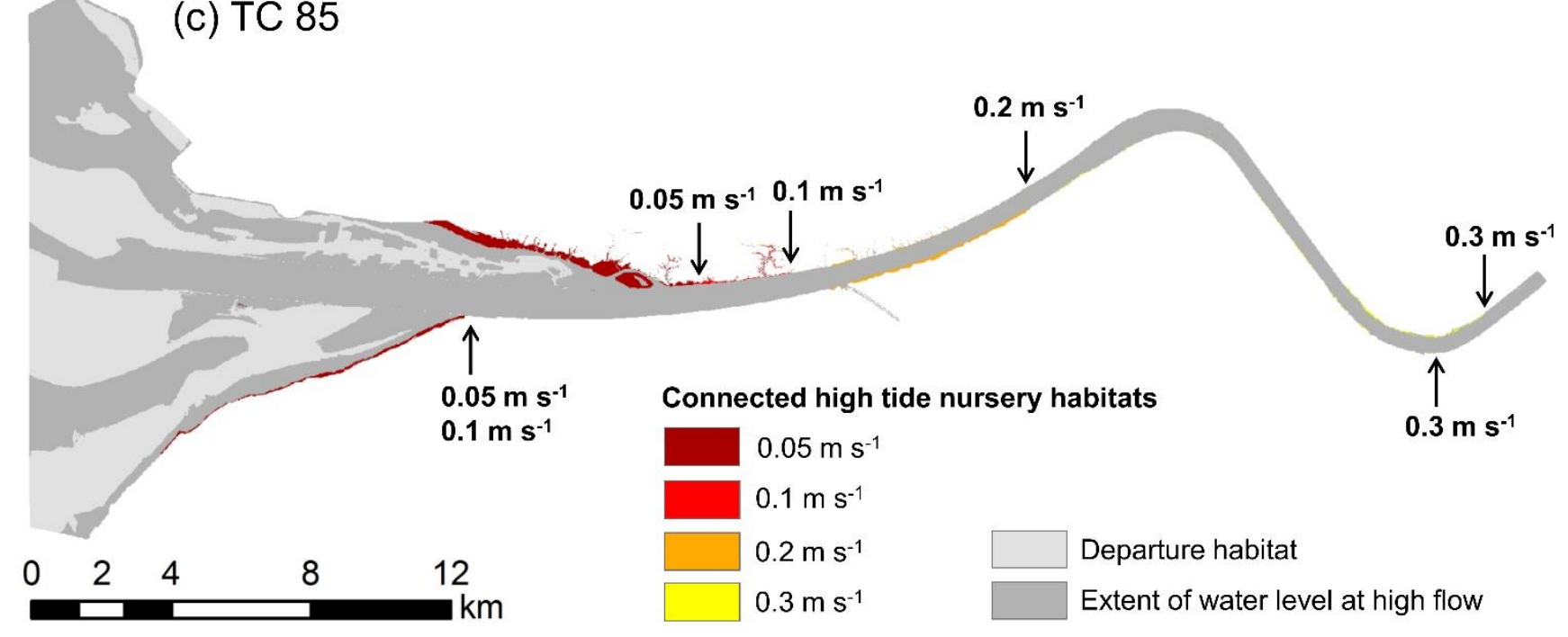




\section{Figure 9}

(a) TC 52

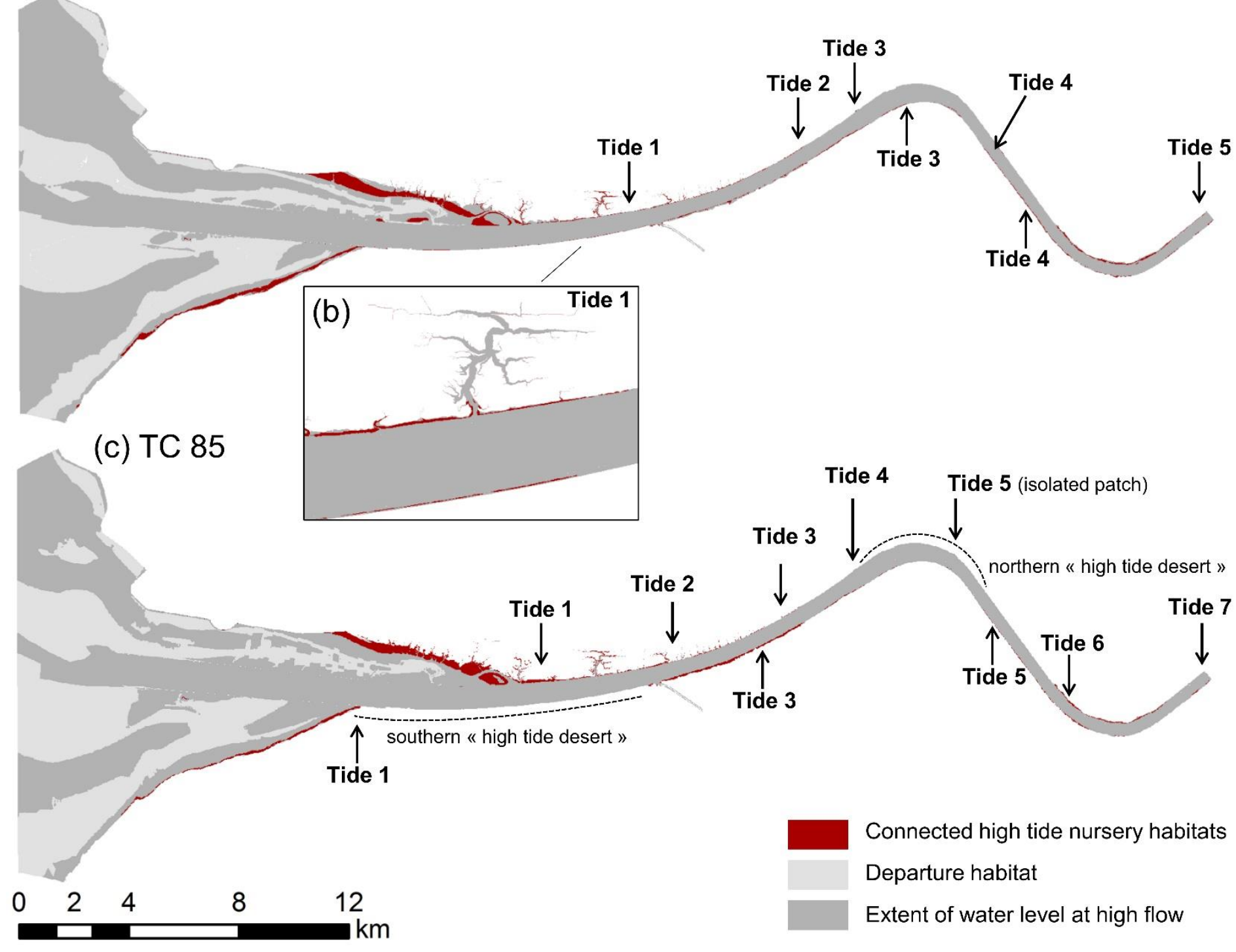

